\title{
PENGALAMAN IBU YANG MEMILIKI ANAK USIA PRASEKOLAH KESULITAN MAKAN DI PAUD IMANUEL PEKANBARU; STUDI FENOMENOLOGI
}

\author{
Raja Fitrina Lestari, Afrila Bella Sari, Meisa Daniati
}

PSIK STIKes HangTuah Pekanbaru

Email: fitrina_raja@yahoo.co.id

\begin{abstract}
Feeding problem is one of problems in preschool who is complained by parents. This research means to acquire the significance experience of mother who has feeding problem child at preschool. This research was conducted through qualitative approach to the design of phenomenology. The methods of data collection are interview and observation. The participants of this research are five mothers of Imanuel PAUD Pekanbaru. The data is processed in verbatim form, and then analyzed by Collaizy technique. This research identified of two themes, namely are: the influence factor offeeding problem, psychologist factor and food rule; the manner of overcome feeding problem are the effort feeding, seduce, giving love, lure and follow the wishes of children. From this research, participant show their children difficulty to eat look from physicologic factor and food setting factor. The way to accoplish difficulty eating who done by participant with possitive way are: follow their child eat together, give love and give attention. While the negative way are: follow their wish of child, feed, tantalize, and force the child to eat. The result of this research expect to be reading material and guideline for parents in dealing feeding problem in children. So preschooler achieve optimal growth.
\end{abstract}

Keyword: Experience, Mother, Preschool, Difficulty Eating

\section{PENDAHULUAN}

Anak merupakan individu yang berada dalam satu rentang perubahan perkembangan yang dimulai dari bayi hingga remaja (Hidayat, 2009). Balita usia 1-5 tahun dapat dibedakan menjadi dua, yaitu toddler (1-3 tahun) dan prasekolah (35 tahun). Toddler dikenal dengan konsumen pasif, sedangkan usia prasekolah lebih dikenal sebagai konsumen aktif. (Proverawati \& Asfuah, 2009).

Masalah kesulitan makan pada anak prasekolah ditemukan lebih dari $20 \%$. Hal ini disebabkan karena anak sudah dapat memilihmilih makanan yang disukai dan hanya mau makan makanan tertentu saja. Ada tiga faktor yang dapat menyebabkan masalah kesulitan makan pada anak yaitu faktor organis (adanya penyakit yang berupa gangguan pencernaan), faktor psikologis (meliputi cara pemberian makan anak, suasana makan dan variasi makanan), dan faktor pengaturan makanan (meliputi jenis makanan yang diberikan pada anak, waktu makan serta frekuensi makan anak) (Fitriani, Febry \& Mutahar, 2009).

Kesulitan makan sering dialami sekitar 25\% pada usia anak, jumlah akan meningkat sekitar $40-70 \%$ pada anak yang lahir prematur atau dengan penyakit kronik. Hal ini sering membuat masalah tersendiri bagi orangtua. Penelitian yang dilakukan di Jakarta menyebutkan pada anak usia prasekolah (4-6 tahun), didapatkan prevalensi kesulitan makan sebesar 33,6\%. Sebagian besar $79,2 \%$ telah berlangsung lebih dari 3 bulan (Hidayati, 2011).

Penelitian yang dilakukan di Kelurahan Tonatan Kecamatan Ponorogo Kabupaten Ponorogo oleh Rohmasari (2013), didapatkan hasil dari 40 responden pada faktor nafsu makan yang berpengaruh terhadap sulit makan balita sebanyak (65\%), dari faktor psikologis anak yang berpengaruh terhadap sulit makan $(62,5 \%)$, dari faktor kondisi fisik anak yang berpengaruh terhadap sulit makan $(57,5 \%)$, dan dari faktor perilaku pemberian makan orang tua pada anak yang berpengaruh terhadap sulit makan $(62,5 \%)$.

Berdasarkan wawancara yang dilakukan dengan ketua RW 17 Kelurahan Sail di dapatkan juga bahwa di kelurahan tersebut belum pernah dilakukan penelitian tentang masalah kesulitan makan pada anak usia prasekolah. Berdasarkan penjelasan di atas, peneliti tertarik untuk melakukan penelitian tentang "pengalaman ibu yang memiliki anak usia prasekolah kesulitan makan di PAUD Imanuel Pekanbaru". 


\section{METODOLOGI PENELITIAN}

Penelitian ini menggunakan metode kualitatif dengan pendekatan fenomenologi.

Instrumen atau alat pada penelitian ini adalah peneliti itu sendiri (Sugiyono, 2012). Peneliti melakukan wawancara dengan orangtua dari 5 anak yang bersekolah di PAUD Imanuel Pekanbaru menggunakan pedoman wawancara dengan sebanyak delapan pertanyaan dan untuk wali kelas dengan tujuh pertanyaan yang menggunakan alat bantu berupa camera digital dan handpone sebagai alat perekam videolaudio dan untuk pengambilan foto. Dalam pengumpulan data ini peneliti dibantu peneliti kedua untuk memfoto dan melakukan perekaman video/audio. Pengumpulan data pada penelitian ini dilakukan dengan metode wawancara dan observasi.

Analisa data pada penelitian ini dilakukan berdasarkan sembilan tahap analisis Collaizi (Saryono \& Anggraeni, 2013), sebagai berikut:

a. Memiliki gambaran yang jelas tentang fenomena yang diteliti, yaitu pengalaman ibu yang memiliki anak usia prasekolah kesulitan makan.

b. Mencatat data yang diperoleh yaitu hasil wawancara dengan partisipan mengenai pengalaman ibu yang memiliki anak usia prasekolah kesulitan makan serta hasil dari catatan lapangan dan observasi sebagai tambahan untuk analisis selanjutnya.

c. Membaca hasil transkrip berulang-ulang agar peneliti lebih memahami pernyataanpernyataan partisipan tentang pengalaman ibu yang memiliki anak usia prasekolah kesulitan makan secara mendalam.

d. Membaca transkrip untuk memperoleh ide yang dimaksud partisipan yaitu berupa kata kunci dari setiap pernyataan partisipan, yang kemudian diberi garis bawah pada pernyataan yang penting agar bias dikelompokkan.

e. Menentukan arti dari setiap pernyataan yang penting dari semua partisipan dan pernyataan yang berhubungan dengan pengalaman ibu yang memiliki anak usia prasekolah kesulitan makan. f. Melakukan pengelompokan data kedalam berbagai kategori untuk selanjutnya dipahami secara utuh dan menentukan tematema utama yang muncul.

g. Peneliti mengintegrasikan hasil secara keseluruhan kedalam bentuk deskripsi naratif mendalam tentang pengalaman ibu yang memiliki anak usia prasekolah kesulitan makan.

h. Peneliti kembali ke partisipan untuk klarifikasi data hasil wawancara berupa transkrip yang telah dibuat kepada partisipan, untuk memberikan kesempatan kepada partisipan menambahkan informasi yang belum diberikan pada saat wawancara pertama atau adai nformasi yang tidak ingin dipublikasikan dalam penelitian.

i. Data baru yang diperoleh saat dilakukan validasi kepada partisipan digabungkan kedalam transkrip yang telah disusun peneliti berdasarkan persepsi partisipan.

\section{Karakteristik Partisipan}

Pada penelitian ini partisipan utama yaitu Ibu berusia 36 tahun yang memiliki anak usia 6 tahun, dengan pendidikan terakhir ibu SMU. Ibu berusia 36 tahun yang memiliki anak usia 5 tahun, dengan pendidikan terakhir ibu SMU.

Ibu berusia 44 tahun yang memiliki anak usia 5 tahun, dengan pendidikan terakhir ibu SMP. Ibu berusia 45 tahun yang memiliki anak usia 5 tahun, dengan pendidikan terakhir ibu SLTA. Ibu berusia 35 tahun yang memiliki anak usia 5 tahun, dengan pendidikan terakhir ibu SMK. Partisipan pendukung yaitu wali kelas anak di PAUD Imanuel berusia 31 tahun dengan pedidikan terakhir SMK.

\section{Tema}

Data penelitian ini didapatkan melalui wawancara mendalam dan catatan lapangan, kemudian dianalisis berdasarkan model analisis dari Collaizi (Saryono \& Anggraeni, 2013). Analisa data dalam penelitian ini menghasilkan dua tema. Dua tema tersebut adalah sebagai berikut. 


\section{Faktor-faktor yang mempengaruhi kesulitan makan}

a. Faktor psikologis

3 dari 5 partisipan mengungkapkan anaknya mengalami masalah kesulitan makan dari faktor psikologis. Berikut beberapa ungkapan dari partisipan:

"Pagi paling sering dia menolak, harus di paksa dia kalo makan pagi”(P1 hal 1)

"Waktu-waktu tertentu aja sih, kalo pagi memang mau dia minta makan. gitukan. terus kalo. kalo siang karna mungkin uda bawak apa kesekolah jajankan. kalo pulang sekolah dia udah agak malas, jadi nanti sekitar jam-jam apa ya. jam-jam 2 saya paksa juga makan"(P2 hal 1)

"(memgangguk) bawak kue karna di rumah udah susu aku kasih kan. di paksa minum susunya. habiskan sama kue nya."(P3 hal 2)

"Teserah aja. mana yang. kalo dia ndak doyan makannya kita tinggalin gitu kita biarkan. pasti udah di buang tu."(P3 hal 2)

Data hasil observasi adalah saat ibu meminta anaknya untuk makan, anak menggelengkan kepala dan membelakangi ibunya. Melihat reaksi anak yang seperti itu, ibupun mendekati anaknya dan menarik pelan kaki anak sambil berkata "cepatlah nak cepatlah nak" sambil merayu dan sedikit memaksa anak membuka mulutnya untuk memakan makanan yang ada disuapan ibu. Akhirnya, anakpun mau memakan makanan walaupun masih memilih sambal mana yang mau dimakan yang ada di dalam piring.

b. Faktor pengaturan makan

4 dari 5 partisipan mengungkapkan anaknya mengalami masalah makan pada jadwal makan pemberian makan. Berikut beberapa ungkapan dari partisipan.

"pagi paling sering dia menolak, harus dipaksa dia kalo makan pagi"(P1 hal 1)

"Waktu-waktu tertentu aja sih, kalo pagi memang mau dia minta makan. gitukan. terus kalo. kalo siang karna mungkin uda bawak apa kesekolah jajankan. kalo pulang sekolah dia udah agak malas, jadi nanti sekitar jam-jam apa ya. jam-jam 2 saya paksa juga makan"(P2 hal 1)

"Ee pagi-pagi yang paling sering malas, makan pagi tu. kan, maunya sarapan dia jangan lah. nasi, padahal mau sekolah itu biar lebih tahan di dalam perutnya maunya nasi lah kan.”(P4 hal 1)

"Yang makan siang, siang kalo pagi sama apa. emang dari, dari bayi pun saya usahakan makan dari pagi. tapi siangnya kadang mungkin udah makan cemilan ntah jajan siang itu agakagak susah, tapi saya usahakan jugak makan siang pokonya ada nasi diperutnya, saya usahakan (mengangguk)"(P5 hal 2)

"Iya, da minta uang, bangun tidur bagi uang mak, ee makan dulu. iya, siap jajan nanti makan. sudah di bohong-bohongi kadang kita"(P4 hal 2)

\section{Cara mengatasi kesulitan makan}

Berbagai cara dilakukan oleh partisipan dalam mengatasi masalah kesulitan makan pada anaknya. Berikut beberapa ungkapan partisipan:

"Iya di suapin kalok mau sarapan"(P1 hal 2)

"Pagi paling sering dia menolak, harus di paksa dia kalo makan pagi"(P1 hal 1)

"Kadang-kadang di iming-imingi jajan gitu kan. nanti habis makan jajan ya. (tersenyum) . kalo. kalo ngga mau makan nanti, ke siapa tu apa. kan ada disitu (menunjuk arah) yang agak cacat lah gitu. nanti kek gitu. kalo ngga mau makan sayur pun nanti kek gitu. (tersenyum) baru mau dia makan. Gitu aja kalo ngasih dia makan. (mengangguk)"(P2 hal 2)

"Kadang-kadang disuap. kalo lagi susah makan. disuap aja (mengangguk). Kalo mau dia, minta sendiri juga. kalo lagi apa. kalo nggak terpaksa saya suapkan daripada ngga makan"(P2 hal 2)

"Sehari. tiga kali. kalo pagi tadi udah sarapan kan. nanti jam-jam. (melihat ke arah jam) jamjam 1 makan lagi. bapak nya pulang kerjakan. sekalian makan sama gitu."(P2 hal 3)

"Waktu-waktu tertentu aja sih, kalo pagi memang mau dia minta makan. gitukan. terus kalo. kalo siang karna mungkin uda bawak apa kesekolah jajankan. kalo pulang sekolah dia udah agak malas, jadi nanti sekitar jam-jam apa ya. jam-jam 2 saya paksa juga makan"(P2 hal 1)

"Kalo makan dia susah makan dia. Cuma itu aja dia kalok. mm apa dia tu payah makan disuapin sampe habis lah gitu kita tunggu-tunggu dia kan. kalok ndak habis kita tengok gini. 
misalnya minta sendiri makan kita liatkan, tapi sambil diperhatikan gitu. habis nggak nasi nya itu. karna dia selalu mau bilang habis nasinya padahal di buang"(P3 hal 1)

"Iya (mengangguk). gitu dia, padahal disimpan disana. Jadi itulah makanya selalu di tengok nasi nya itu. da habis nggak! Udah mak! Kalo di tengok kan. diantar ke dapur. jadi makanya selalu diperhatikan dia makan, kadangkadang di tunggu gini. kalo ndak apa kesukaannya misalnya se.semacam dia ini kan. daun ubi tumbuk."(P3 hal 1)

"(memgangguk) bawak kue karna di rumah udah susu aku kasih kan. di paksa minum susunya. habiskan sama kue nya.”(P3 hal 2)

"Ooh itu. ini anak saya kalok apabila dia ee menolak untuk dikasih makan. kadang saya. ee apa dulu. saya berikan kasih sayang dulu, saya sayang-sayang dia kan (mengangguk). terus udah siap ee ibuknya sayang-sayang, makan lah nak makan lah nak, kadang dimakan, terus belum habis lagi, udah mak katanya kan, jangan gitu lah siap makan nanti biar pergi kita jajan, yok habiskan nak habiskan nak. kadang kek gitu lah caranya sampai habis lah nasinya di buat. gitu.”(P4 hal 1)

"(Mengangguk) iya lebih sering disuapin yang penting biar bisa masuk kedalam perutnya kan. disuapin aja sambil disayang-sayang sambil di iming-imingi sesuatu. (tertawa)"(P4 hal 2)

"Kita usahakan apa maunya ditanya ibaratnya kita masak yang ini dia nggak sukak, kita usahakan apa maunya ikan apa kesukaannya kek manapun berusaha ntah satu sendok pun yang penting ada isi perutnya"( $\mathrm{P} 5$ hal 1)

"Ntah satu sendok kita berusaha ntah kek mana caranya biar bisa dia makan terpaksa disuap, tapi kalo selera ikan mana yang maunya. dia makan sendiri"'(P5 hal 2)

"Ya dirayu lah kek mana ntah apalah. soalnya dia agak susah jugak"(P5 hal 2)

"Di pujuk dulu ibaratnya. waktu jam makan kami makan lah ditanyak ayok makan nak, nggak mau aku, sedikitpun, tak mau aku ikannya itu.. mau nya apa? Mau nya itu. diusahakanlah dirayu makan.”(P5 hal 3)
Data hasil observasi adalah ibu merayu anak sambil menyuapi anak agar mau makan. Sambil mengiming-imingi akan membeli es krim kalau makanan yang ada dipiring dihabiskan semua oleh anak.

Berikut wawancara dengan partisipan pendukung:

"Kalo J (inisial nama anak) kalo bawak makanan-makanan gitu mereka sukak gini disini nggak mau makan sendiri, istilahnya kasih teman gitu. jadi habis bukan habis karna makan sendiri. jadi “em heei aku mau bagi ini mau ndak?" gitu. mau bagi. Jadi ceritanya mereka ini mau bagi tu karna harus habis (tersenyum) ceritanya harus habis (mengangguk) bukan karna ya mentangmentang baik lah segala macam, tapi mereka mungkin dari. ee dari guru jugak ditekankan makanan itu nggak boleh sisa. harus dihabiskan. (tersenyum)"(PP1 hal 1)

"Nggak, kalo anak-anak ini kan nggak boleh kita paksa apalagi kan PAUD, ngga boleh kita paksa mereka (menggeleng), anak SD harus ini harus, nggak boleh. kan PAUD itu bermain sambil belajar. ceritanya kan begitu. jadi kalo memang mereka bilang nggak mau lagi ngga boleh dipaksa. tapi penekanan dari kita makanan itu nggak boleh sisah (mengangguk)"(PP1 hal 2).

\section{HASIL DAN PEMBAHASAN}

Analisa data dalam penelitian ini menghasilkan dua tema yaitu faktor yang mempengaruhi kesulitan makan dan cara mengatasi kesulitan makan.

\section{1. faktor yang mempengaruhi kesulitan makan}

Faktor-faktor yang mempengaruhi kesulitan makan dapat berupa faktor psikologis dan faktor pengaturan makanan. Proverawati \& Asfuah (2009) menjelaskan bahwa salah satu faktor yang mempengaruhi kesulitan makan adalah faktor psikologis. Contohnya, seperti anak terlalu dipaksa menghabiskan makanan dan makanan yang disajikan tidak sesuai dengan yang diinginkan anak. Menurut Redaksi Health Secret (2013), faktor yang mempengaruhi sulit makan salah satunya adalah faktor psikologis. Penolakan makan biasanya bermula pada anak berusia 3 
sampai 4 tahun. Anak akan semakin menolak untuk makan jika orangtuanya memaksa dalam memberikan makan. Umur anak partisipan adalah 5 sampai 6 tahun dan ada beberapa partisipan yang memaksa agar anak mau makan di jadwal makan.

Partisipan menyatakan bahwa anak paling sering menolak makan saat pagi hari sebanyak 2 partisipan sehingga harus dipaksa untuk memulai makan pagi dan anak pada akhirnya mau makan, sedangkan untuk makan siang dan makan malam anak tidak bermasalah. Partisipan lain menyatakan bahwa anak di paksa untuk memulai makan siang sebanyak 2 partisipan sehingga anak pada akhirnya juga mau makan siang, serta partisipan lain menyatakan bahwa jika anak tidak menyukai makanan yang disajikan sehingga membuat anak menjadi membuang makanan tersebut.

Jadi, faktor psikologis yang dialami anak berdasarkan wawancara yang telah dilakukan oleh peneliti dan partisipan, didapatkan bahwa anak lebih sering menolak saat diberi makan di waktu-waktu tertentu. Hal ini bisa disebabkan oleh makanan yang disajikan tidak sesuai dengan keinginan anak.

Menurut Fitriani, Febry \& Mutahar (2009), faktor lain yang mempengaruhi kesulitan makan adalah faktor pengaturan makanan contohnya waktu dalam pemberian makan anak dan frekuensi makan anak. Frekuensi makan adalah jumlah makan sehari-hari atau biasa juga disebut pola makan. Pola makan yang ideal menurut Tilong (2014) adalah dua kali sehari, tiga kali sehari dan lebih dari tiga kali sehari. Faktorfaktor yang mempengaruhi pola makan menurut Aini (2013), salah satunya adalah faktor pendidikan. Umumnya pendidikan partisipan adalah tamatan SMU sederajat sehingga hanya satu partisipan yang membiarkan anak jajan sebelum jadwal makan. Menurut Sunartyo (2008), sebelum jadwal makan tiba jangan berikan anak makanan lain yang membuat anak menjadi kenyang agar anak tetap mau makan nasi pada jadwal makan karena hal ini akan berpengaruh pada pengaturan makan anak. Menurut Redaksi Health Secret (2013) jangan biasakan anak untuk ngemil, batasi makanan selingan yang tidak mengandung kalori karena akan mengganggu selera makan di jam makan utama. Hal ini juga didukung oleh Judarwanto (2004) yang menyatakan bahwa hindari pemberian makanan kudapan/jajanan menjelang makan karena dapat mengurangi selera makan anak. Sementara partisipan menyatakan bahwa anak susah makan pagi, susah makan siang dan suka jajan.

Kesulitan makan adalah jika anak tidak mau atau menolak untuk makan, atau mengalami kesulitan mengonsumsi makanan atau minuman dengan jenis dan jumlah sesuai usia secara fisiologis (alamiah dan wajar), yaitu mulai dari membuka mulutnya tanpa paksaan, mengunyah, menelan hingga sampai terserap dipencernaan secara baik tanpa paksaan dan tanpa pemberian vitamin dan obat tertentu (Hidayati, 2011). Sementara hasil penelitian menunjukkan bahwa anak hanya mengalami masalah dalam memulai untuk makan.

\section{Cara mengatasi kesulitan makan}

Menurut Sunartyo (2008), salah satu cara mengatasi anak kesulitan makan adalah dengan cara jadwal makan anak disamakan dengan jadwal makan orang dewasa agar anak lebih bersemangat untuk menghabiskan makanan. Hal ini juga di dukung oleh Redaksi Health Secret (2013) yaitu salah satu cara memotivasi anak agar anak berselera makan adalah makan bersama. Penelitian membuktikan keluarga yang selalu makan bersama minimal satu kali sehari akan mengonsumsi makanan yang lebih bergizi dibanding yang tidak melakukan makan bersama. Selain itu bisa juga dilakukan dengan cara tidak memaksa anak yang menolak makan. Sunartyo (2008) juga menjelaskan salah satu upaya untuk mengatasi sulit makan adalah dengan cara jangan memaksa anak untuk menghabiskan makanan.

Beberapa cara untuk mengatasi kesulitan makan yang dilakukan oleh orangtua ini memiliki beberapa dampak diantaranya yaitu: menyuapkan makanan secara paksa saat anak tidak mau makan, ini sangat berbahaya bagi kesehatan. Pemberian makan makanan atau minuman secara paksa, atau ketika anak sedang menangis dan berontak, memiliki risiko terjadinya aspirasi 
(masuknya) makanan/minuman ke saluran napas atau tersedak. Kedua hal ini dapat berakibat fatal bagi anak, apalagi bila masih bayi (Kanal, 2016). Selain itu cara orang tua dengan memberikan makanan kesukaan anak dan makanan yang ituitu saja, juga berdampak buruk, berdasarkan penelitian yang dilakukan Kurniasih et al pada tahun 2010, anak usia 3-5 tahun umumnya mengalami permasalahan pola makan, salah satunya picky eater (menyukai makanan yang tertentu saja). Akibat permasalahan makanan ini, jenis makanan yang dikonsumsi anak menjadi tidak bervariasi dan kandungan gizinya tidak seimbang (Saraswati, 2012). Penelitian ini hanya tiga partisipan yang melakukan cara yang benar, yaitu dengan mengajak anak makan bersama dengan anggota keluarga yang lainnya dan memberikan pujian (memberikan kasih sayang dan merayu anak).

Partisipan menyatakan anak makan bersama pada saat jam makan malam dengan ayahnya. Sedangkan partisipan yang lain melakukan cara mengatasi kesulitan makan dengan cara merayu anak dan memberikan kasih sayang sama halnya dengan memberi pujian. Hal ini sesuai dengan konsep yang dikemukakan oleh Irianto (2007) yang menjelaskan bahwa apabila anak mampu menghabiskan porsi makanan yang diberikan, berilah pujian yang akan menyenangkan hati anak. Hal ini juga sejalan dengan konsep Redaksi Health secret (2013) yaitu ciptakan suasana makan yang menyenangkan, ajak anak makan dengan penuh kasih sayang. Selain itu partisipan yang lain melakukan cara mengatasi kesulitan makan dengan mengikuti makanan kesukaan anak, menyuapi anak, mengiming-imingi, dan memaksa anak untuk makan.

Berdasarkan penjelasan diatas dapat disimpulkan bahwa cara orangtua dalam mengatasi kesulitan anak dalam memulai untuk makan berbeda-beda antara orangtua satu dan lainnya. Tidak semua cara yang dilakukan oleh orang tua berdampak baik terhadap anak. Seperti memaksa anak untuk makan dan memberikan makanan kesukaan anak.

\section{KESIMPULAN DAN SARAN}

\section{Kesimpulan}

Berdasarkan hasil penelitian tentang pengalaman ibu yang memiliki anak usia prasekolah kesulitan makan di PAUD Imanuel Pekanbaru, maka dapat disimpulkan sebagai berikut:

a. Faktor-faktor yang mempengaruhi anak usia prasekolah kesulitan makan yaitu: faktor psikologis dan faktor pengaturan makanan. Faktor psikologis meliputi; anak dipaksa untuk makan, tidak menyukai makanan yang disajikan. Sedangkan pengaruh dari faktor pengaturan makanan yaitu anak susah makan pagi, susah makan siang dan anak suka jajan.

b. Cara mengatasi kesulitan makan yang dilakukan oleh ibu pada penelitian ini ada yang positif dan ada yang negatif. 3 dari 5 partisipan sudah melakukan cara yang benar dalam mengatasi kesulitan makan seperti mengajak anak makan bersama, meberikan kasih sayang dan merayu (memberi pujian) pada anak.

\section{Saran}

a. Bagi institusi pendidikan STIKes Hang Tuah Pekanbaru

Berdasarkan hasil penelitian ini didapatkan bahwa pengalaman ibu yang memiliki anak usia prasekolah dengan kesulitan makan bervariasi antara ibu satu dan lainnya. Sehingga penelitian ini dapat menjadi bahan pertimbangan untuk dunia pendidikan terutama dalam hal menggali lebih banyak masalah-masalah pada anak.

b. Bagi PAUD

Sekolah merupakan tempat kedua setelah keluarga bagi anak prasekolah dalam menjalani fase tumbuh kembang anak. Guru dapat berperan sebagai orangtua maupun konselor di sekolah terkait dalam menjalani fase tumbuh kembang anak. Penelitian ini dapat memberikan informasi kepada PAUD sebagai bahan konseling untuk orangtua.

c. Bagi Ibu

Berdasarkan hasil penelitian ini diketahui bahwa terdapat berbagai cara yang dilakukan oleh ibu dalam menghadapi anak usia prasekolah dengan kesulitan makan sebagian besar melalui 
cara yang positif. Harapan terbesar peneliti, ibu dapat menjalankan cara tersebut dengan lebih baik.

d. Bagi peneliti selanjutnya

Hasil penelitian ini merupakan penelitian dasar untuk perkembangan peneliti selanjutnya. Peneliti dapat menggali lebih dalam lagi tentang pengalaman orangtua khususnya ibu yang memiliki anak usia prasekolah dengan masalah yang lainnya.

\section{DAFTAR PUSTAKA}

Aini, M. (2013). Pola makan. Diperoleh dari http://repository. usu.ac.id/bitstream/123456789/39322/4/ Chapter\%2011.pdf. diakses tanggal 31 Juli 2016.

Fitriani, F., Febry, F., \& Mutahar, R. (2009). Gambaran Penyebab Kesulitan Makan pada Anak Prasekolah Usia 3-5 Tahun di Perumahan Top Amin Mulya Jakabaring Palembang Tahun 2009. Jurnal Publikasi Ilmiah Fakultas Kesehatan Masyarakat Universitas Sriwijaya.

Hidayat, A. A. A. (2009). Pengantar Ilmu Keperawatan Anak. Jakarta: Salemba Medika.

Hidayati, N. L. (2011). Mengatasi Anak Susah Makan. (Ed). Yogyakarta: ANDI.

Irianto, D. P. (2007). Panduan Gizi Lengkap Keluarga dan Olahragawan. (Ed). Yogyakarta: ANDI.

Judarwanto, W. (2004). Mengatasi Kesulitan Makan Pada Anak. Jakarta: Puspa Swara.

Kanal. 8 Kebiasaan Buruk Orangtua yang Membahayakan Kesehatan Anak. Diperoleh Lari http://www.indexberita.net/export/pdf/1 513564219. diakses tanggal 2 Agustus 2016.

Patmonodewo, Soemiarti. (2008). Pendidikan Anak Prasekolah. Jakarta: PT Rineka Cipta.
Proverawati, A., \& Siti A. (2009). Buku Gizi untuk Kebidanan. Yogyakarta: Nuha Medika

Redaksi Health Secret. (2013). Siasat Gizi Anak Lebih Sehat Supaya Pintar di Sekolah. Jakarta: PT Gramedia.

Rohmasari, A. (2013). Faktor-Faktor yang Mempengaruhi Sulit Makan pada Balita di Kelurahan Tonatan, Kecamatan Ponorogo, Kabupaten Ponorogo. (Doctoral dissertation, Universitas Muhammadiyah Ponorogo).

Saraswati, D.P.M. (2012). Gambaran Perilaku Picky Eater dan faktor yang Melatar Belakanginya pada Siswa Paud Kasih Ananda Bekasi Tahun 2012. Diperoleh dari

http://lib.ui.ac.id/file?file=digital/20356 239-S-Dian\%20Putri\%20

Mumpuni\%20Saraswati\%20T.pdf.Diaks es pada tanggal 2 agustus 2016.

Saryono \& Anggraeni, M. D. (2013). Metodologi Penelitian Kualitatif dan Kuantitatif dalam Bidang Kesehatan. Yogyakarta: Nuha Medika.

Sugiyono. (2012). Memahami Penelitian Kualitatif. Bandung: Alfabeta.

Sunartyo, N. (2008). Panduan Merawat Bayi \& Balita Agar Tumbuh Sehat dan Cerdas. Jogjakarta: DIVA Press.

Sutomo, B., \& Anggraini, D. Y. (2010). Menu Sehat Alami untuk Batita \& Balita. Jakarta: Demedia.

Telaumbanua, L. K. (2013). Faktor-faktor yang Mempengaruhi Sulit Makan pada Usia Prasekolah di TK Islam Nurul Hikmah Bantar Gebang Bekasi Tahun 2013. Jurnal Kesehatan AYURVEDA 1.1

Tilong, A. D. (2014). Ipahasia Pola Makan Sehat. Jogjakarta: FlashBooks. 